\title{
Hospital Practice
}

\section{Attitudes to a hospital based terminal care scheme}

\author{
C.M. McKee ${ }^{1}$, G. Rajaratnam ${ }^{2}$ and L. Lessof ${ }^{1}$ \\ ${ }^{1}$ Islington District Health Authority and ${ }^{2}$ Ealing District Health Authority, London, UK.
}

\begin{abstract}
Summary: Two years after the establishment of a terminal care support team, the team perceived that a number of patients were not being referred to them, and many of those seen were referred at a very late stage in their illness. We sent a questionnaire to all clinicians and ward sisters in the district to elicit their knowledge of the team and attitudes to their role. Although most respondents had cared for terminal patients in the previous 6 months, over a quarter were not aware of the existence of the team. The lack of awareness was most common among junior medical staff, many of whom were spending relatively short times in the district. The study indicated a requirement for good communication between terminal care teams and other professionals and a need to inform junior staff about available facilities. A requirement for training in terminal care was also identified.
\end{abstract}

\section{Introduction}

In 1983 a hospital based terminal care support group was established in an inner London district. The district contains two acute hospitals with a total of 720 beds. The team comprised two Macmillan sisters supported informally by three consultants. They perceived that a number of patients who might have benefited from their services were not being referred, and others were being referred too late in their illness to receive any practical help. A separate study had shown that the 240 patients seen annually represented about $35 \%$ of those dying from cancer who were in contact with the hospitals concerned, and $25 \%$ of those seen were referred in the week prior to death. As part of an evaluation of the team in 1986, an attempt was made to examine the low referral rate by surveying the awareness of the team among medical and nursing. staff, and their attitudes to terminal care.

\section{Methods}

A questionnaire was designed to study the awareness of the existing terminal care support system, and to assess the attitudes to terminal care in

Correspondence: C.M. McKee, M.B., B.Ch., M.Sc., M.R.C.P. (UK), Islington Health Authority, District Offices, Dartmouth Park Hill, London N19 5HT, UK. Accepted 16 March 1988 general. In particular the questions examined the perceived needs of patients and both the benefits and problems which had occurred as a result of referral to the team. Following a pilot study it was sent to each member of the medical staff with direct patient contact and to each ward sister in the two hospitals. A total of 204 questionnaires were distributed. A reminder was sent to non-responders after two weeks.

\section{Results}

There was a $60 \%$ response to the questionnaire. This was higher among senior medical staff and lower among juniors and ward sisters although these differences were not significant (Table I).

Table I Percentage response among different grades of staff

\begin{tabular}{lcc}
\hline Grade & $\begin{array}{c}\text { Number } \\
\text { sent }\end{array}$ & $\begin{array}{c}\text { Percentage } \\
\text { response }\end{array}$ \\
\hline Consultant & 51 & 71 \\
Senior registrar & 15 & 73 \\
Registrar & 24 & 50 \\
Senior house officer & 29 & 62 \\
Junior house officer & 19 & 58 \\
Clinical assistant & 18 & 50 \\
Ward sister & 50 & 52 \\
\hline
\end{tabular}

(C) The Fellowship of Postgraduate Medicine, 1988 
Within medical specialities the response was highest among those who would be expected to manage terminally ill patients most frequently, such as oncologists and geriatricians, and lowest among those who would not, such as orthopaedic surgeons.

Seventy-three per cent of respondents had been involved in the management of terminal cancer patients in the preceding 6 months, and $44 \%$ had treated more than six patients in this period.

The need for specialized terminal care services was accepted by $97 \%$ of respondents.

Only $71 \%$ were aware of the existence of the service although it had been operating for over 2 years. The level of awareness was highest among ward sisters and lowest among junior medical staff.

Of those who were aware of the team $80 \%$ had referred patients to it, and $83 \%$ of them felt that the patient had benefited as a result. The remainder were uncertain, and no-one thought that referral had been detrimental.

A third of respondents felt that specialized terminal care had caused problems at times and these were mostly due to difficulties of communication between the professionals involved. Only $23 \%$ had undergone any specific training in terminal care. The percentage with training was highest among consultants $(33 \%)$ and lowest among junior house officers $(9 \%)$.

The major problems faced by the patient, as perceived by respondents, were pain control, gastrointestinal symptoms and coming to terms with the illness. Less importance was attributed to confusion, spiritual support and mobility.

The most important problems considered to be faced by the family were the requirement for bereavement counselling and breaks from caring for the patient.

\section{Discussion}

The proportion of patients dying in hospital has risen substantially in recent years. ${ }^{1}$ A DHSS working party chaired by Professor Eric Wilkes recommended in 1980 that district general hospitals should play an important part in the provision of terminal care services in the absence of a local

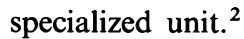

Inadequacies in the provision of terminal care have been demonstrated in a number of studies ${ }^{3,4}$ although it has been shown that increased awareness of the needs of terminal patients has improved the quality of care. ${ }^{5}$
This study confirms that a considerable proportion of medical and nursing staff in acute hospitals have contact with patients dying from cancer, and they identify a need for specialized services to assist in the management of these patients.

The team recognized that not all patients dying from cancer require specialized terminal care services but they had formed the impression that some patients who would have benefited from them had not been referred. This study suggests that this was partly due to clinicians' lack of awareness of the service. Most of those who knew of it had used it, and considered that it had helped the patient.

The study emphasizes the importance of ensuring that the availability of existing services is made known to staff and that special efforts are required to inform the most mobile groups of staff who may spend only a few months at a hospital on a locum or rotational appointment.

Other studies have drawn attention to the main difficulties associated with a specialized terminal care service. ${ }^{6}$ Many professionals have difficulty coping with the emotional distress of patients and with their reactions. This can lead to communication problems between staff. There may also be a failure to recognize the complementary roles which individuals may have in meeting the full range of patients' needs.

The team accepted referrals from any member of the medical or nursing staff, although it was understood that referral was with the consent of the consultant responsible for the patient.

In this study some referring teams had abdicated all responsibility for the patient to the specialized team and others had retained control of the patient's management and considered that their role conflicted with that of the team. Outside these extremes however, there were indications of a clear perception that a comprehensive terminal care programme requires to provide not only pain and symptom control but also a wide range of support in terms of emotional problems, bereavement counselling, and, more generally, 'caring for the carers'.

The study also highlights the need for training, especially of junior medical staff and, by extension, medical students, to provide not only the clinical skills required in terminal care but also to improve understanding of the wider needs of terminal patients. It is likely that terminal care services in the future will have to respond to the needs of patients dying from AIDS, many of whom will be young men. This will increase the requirement for training in terminal care. 


\section{References}

1. Haines, A. \& Booroff, A. Terminal care at home: perspective from general practice. $\mathrm{Br} \mathrm{Med} J$ 1986, 292: 1051-1053.

2. Wilkes, E. Report of the Working Group on terminal care. The Standing Medical Advisory Committee, DHSS, London, 1980.

3. Hinton, J. Comparison of places and policies for terminal care. Lancet 1979, i: 890-894.

4. Parkes, C.M. Home or hospital? Terminal care as seen by surviving spouses. $J R$ Coll Gen Pract 1978, 28: 19-30.

5. Parkes, C.M. Terminal care: hospital or hospice. Lancet 1985, i: 155-157.

6. Herxheimer, A., Begent, R., MacLean, D. et al. The short life of a terminal care support team: experience at Charing Cross Hospital. Br Med J 1985, 290: 1877-1879. 